\title{
AKULTURASI ISLAM DENGAN BUDAYA JAWA: STUDI FOLKLORIS TRADISI TELONAN DAN TINGKEBAN DI KEDIRI JAWA TIMUR
}

\author{
Septiana Purwaningrum ${ }^{1}$, Habib Ismail ${ }^{2}$ \\ ${ }^{I}$ Institut Agama Islam Negeri Kediri Jawa Timur \\ ${ }^{2}$ Institut Agama Islam Ma'arif NU (IAIMNU) Metro Lampung \\ * CORRESPONDENCE: $\square$ septianamanisdewe@gmail.com
}

\begin{abstract}
This article aims to describe the symbolic meaning of the acculturation Telonan and Tingkeban which is believed and preserved by the people of Kunti-Mranggen Village, Kediri, Indonesia. This study uses a type of qualitative research with a folklore approach. This research was conducted for one year using the method of collecting data through interviews, observation, and documentation. In addition to being a research instrument, researchers also participated in the telonan and tingkeban culture with the aim of finding the comprehensive meaning of the object under study. Data analysis in this study uses the deductive method with source triangulation as the checker of the data validity. The results of this study are: 1) Telonan is an activity of praying for pregnant women and their babies during the age of the womb-reaching 3 months into 4 months. While Tingkeban is carried out when the womb reaches 7 months. This activity is carried out with the aim that mothers and babies are always given safety and health by God, as well as fluency in the process of giving birth to the fetus later; 2) In carrying out the telonan and tingkeban several Javanese foods such as jenang abang, jenang putih, buceng ketan, keleman, cucumber, sego golong, sego semaron, sego rogoh, gedhang setangkep, dawet, and rujak are each of these ingredients has symbolic meaning; 3) The values that emerge from the telonan and tingkeban traditions include the value of helping, harmony, friendship, hablumminallah and hablumminannas.
\end{abstract}

Artikel ini bertujuan untuk mendeskripsikan makna simbolik dari akulturasi "Telonan dan Tingkeban" yang diyakini dan dilestarikan oleh masyarakat Dusun Kunti, Mranggen Kediri. Penelitian ini menggunakan jenis penelitian kualitatif dengan pendekatan folklor. Selain menjadi instrumen penelitian, peneliti juga berpartisipasi dalam budaya telonan dan tingkeban tersebut dengan tujuan menemukan makna yang komprehensif dari obyek yang diteliti. Analisis data dalam penelitian ini menggunakan metode deduktif dengan triangulasi sumber sebagai pengecek keabsahan datanya. Hasil penelitian ini adalah: 1) Telonan adalah kegiatan mendoakan ibu yang sedang hamil beserta bayi yang dikandungnya saat usia kandungan mencapai 3 bulan memasuki 4 bulan. Sedangkan Tingkeban dilaksanakan pada saat usia kandungan mencapai 7 bulan. Kegiatan ini dilaksanakan dengan tujuan agar ibu dan bayi senantiasa diberi keselamatan dan kesehatan oleh Allah, serta kelancaran dalam proses melahirkan janinnya nanti; 2) Dalam pelaksanaan telonan \& tingkeban ini dihidangkan beberapa jenis makanan khas Jawa seperti jenang merah, jenang putih, buceng ketan, keleman, timun, sego golong, sego semaron, sego rogoh, gedhang setangkep, dawet, dan rujak yang masingmasing bahan tersebut memiliki makna simbolik; 3) Nilai-nilai yang muncul dari tradisi telonan dan tingkeban di antaranya nilai tolong-menolong, kerukunan, silaturrahim, hablumminallah dan hablumminannas.

\section{Article Info}

Article History

Received : 25-05-2019,

Revised : 14-06-2019,

Accepted : 15-06-2019

\section{Keywords:}

Acculturation ;

Islam ;

Javanese Culture ;

Folklore ;

Telonan;

Tingkeban;

\section{HistoriArtikel}

Diterima :25-05-2019

Direvisi : :14-06-2019

Disetujui :15-06-2019

\section{Kata Kunci:}

Akulturasi;

Islam;

Budaya Jawa;

Folklor;

Telonan;

Tingkeban; 


\section{A. Pendahuluan}

Islam masuk ke Indonesia melalui kontak dagang dan berlangsung mulai abad ke-7 sampai dengan abad ke-14. Proses Islamisasi dilakukan dengan berbagai cara seperti perdagangan, perkawinan, politik, pendidikan, serta budaya. Agama Islam mudah diterima oleh masyarakat Indonesia. ${ }^{1}$ Agama dan kebudayaan Islam yang masuk ke Indonesia mempengaruhi kebudayaan asli Indonesia, sehingga menimbulkan akulturasi. Akulturasi tersebut menimbulkan corak baru kebudayaan Indonesia. Akulturasi dapat dilihat dari berbagai bidang seperti seni bangunan, sastra, seni rupa, seni musik, dan sistem pemerintahan. ${ }^{2}$

Akulturasi Islam dengan budaya lokal merupakan bentuk dari pelestarian budaya lokal. Hal tersebut dibenarkan asal tidak bertentangan dengan syariat Islam. Dengan demikian, jelaslah perjalanan sejarah rekonsiliasi antara Islam sebagai agama dan budaya lokal yang melingkupinya serta adanya landasan hukum legitimatif dari syara' berupa 'urf dan maslahah. Oleh karena itu, strategi pengembangan budaya Islami di Indonesia yang multi etnis dan budaya, pendekatan budaya tanpa meninggalkan nilai-nilai spirit Alquran adalah cara yang paling baik. Islamisasi bukanlah harus Arabisasi, karena Islam adalah agama yang menyeluruh dalam budaya, sikap, dan mentalitas.

Peradaban dan kebudayaan dibentuk dari tata nilai yang luhur oleh masyarakat setempat dan diwariskan secara turun temurun dari generasi ke generasi berikutnya. Nilai dan norma itu digunakan untuk menjaga keseimbangan tatanan kehidupan masyarakat. Nilai dan norma tersebut pada akhirnya menjadi adat istiadat yang dilestarikan oleh masyarakat.

Indonesia adalah negara yang sangat kaya dan beragam, baik dalam hal sumber daya alam, bahasa, suku, maupun budaya. Adat-istiadat setiap daerah di Indonesia memiliki keunikan masingmasing sesuai dengan letak geografis, keadaan alam, serta kondisi dan cara berpikir masyarakat.

Tata nilai atau tata norma yang dilakukan masyarakat Jawa dalam bentuk upacara tradisional merupakan manifestasi tata kehidupan masyarakat Jawa yang dalam kehidupan sehari-hari selalu hidup cermat, hati-hati, dan selalu eling. ${ }^{3}$ Nilai-nilai dan norma-norma Jawa lahir sesuai dengan kebutuhan masyarakatnya. Adat istiadat masyarakat Jawa diwujudkan dalam berbagai kegiatan salah satunya upacara ritual.

Ada banyak rangkaian upacara tradisional adat Jawa sejak ibu mulai hamil, sampai melahirkan anaknya. Desa mawa cara, negara mawa tata; artinya, setiap desa mempunyai cara sendirisendiri, setiap negara mempunyai aturan sendiri-sendiri. Ada variasi atau perbedaan dari berbagai upacara antar daerah. Umumnya, upacara ini dilakukan dalam bentuk selametan, untuk memohon keselamatan pada Tuhan YME.

Hal inilah yang menarik minat penulis untuk melakukan penelitian guna memahami lebih mendalam akulturasi Islam dengan budaya lokal daerah di Indonesia, khususnya Jawa Timur. Peneliti mengambil setting di salah satu daerah di wilayah Kediri yaitu Dsn. Kunti-Ds. MranggenKec. Purwoasri dengan pertimbangan di dusun ini telah berkembang sebuah budaya yang unik yang di dalamnya sarat dengan nilai-nilai yang masih berkembang dan konsisten dilaksanakan masyarakat daerah tersebut meski dalam pelaksanaannya telah mengalami pergeseran nilai. Budaya

1 "PENDIDIKAN ISLAM DI INDONESIA DALAM LINTASAN SEJARAH (Perspektif Kerajaan Islam) | Nursyarief | Lentera Pendidikan : Jurnal Ilmu Tarbiyah Dan Keguruan," accessed June 11, 2019, http://journal.uin-alauddin.ac.id/index.php/lentera_pendidikan/article/view/533.

2 "REKONSTRUKSI HUKUM ISLAM DAN IMPLIKASI SOSIAL BUDAYA PASCA REFORMASI DI INDONESIA | Shulhan | KARSA: Journal of Social and Islamic Culture,” accessed June 11, 2019, http://ejournal.stainpamekasan.ac.id/index.php/karsa/article/view/41.

\footnotetext{
${ }^{3}$ Nanik Herawati, Mutiara Adat Jawa 2 (Klaten: PT Intan Pariwara, 2010), 1.
} 
yang penulis maksud adalah selamatan Telonan dan Tingkeban (tradisi mendoakan ibu yang sedang hamil). Berdasarkan latar belakang masalah di atas, penulis melakukan penelitian folklor dengan topik "Akulturasi Islam dengan Budaya Jawa (Studi Folklor tentang Budaya Telonan dan Tingkeban di Dusun Kunti-Desa Mranggen-Kecamatan Purwoasri-Kabupaten Kediri-Jawa Timur)”.

Kajian tentang Telonan dan Tingkeban telah dilakukan oleh beberapa peneliti sebelumnya, seperti penelitian yang dilakukan oleh Iswah Adriana yang membahas Telonan dan Tingkeban yang dikonfirmasi dengan sumber ajaran Islam baik Alquran maupun Hadits menggunakan kajian analisis isi. Di dalam kajiannya tersebut Iswah menyimpulkan bahwa pada awalnya acara Telonan syarat akan kemusyrikan, akan tetapi ketika Islam datang dan memasukkan nilai-nilai Islam ke dalamnya, maka tradisi Telonan bisa atau boleh dilakukan oleh umat Islam. ${ }^{4}$

Selain itu terdapat kajian lain yang dilakukan oleh Andriani Purwastuti dan Rukiyati yang menginterpretasikan makna dibalik ritual-ritual yang dilakukan pada acara Telonan dan Tingkeban. Dalam penelitiannya tersebut, penulis mendapati bahwa acara siraman dan mengganti pakaian sampai tujuh kali memiliki makna berupa kesederhanaan, kebahagiaan lahir batin, kesempurnaan hidup, kesucian hati, pengakuan adanya zat yang lebih tinggi, dan kesederhanaan. ${ }^{5}$

Berdasarkan hal tersebut, peneliti belum mendapatkan kajian yang sama dengan apa yang dilakukan penulis lainnya. Kajian pertama menggunakan pendekatan analisis konten yang menitikberatkan pada kajian konfirmatif terhadap sumber ajaran Islam, yaitu Alquran dan Hadits dengan budaya Telonan dan Tingkeban, adapaun kajian kedua lebih menitikberatkan pada interpretasi peneliti terhadap nilai etik yang terdapat pada tradisi Telonan dan Tingkeban. Sedangkan tulisan yang peneliti lakukan lebih kepada nilai-nilai tradisi Telonan dan Tingkeban yang diungkap melalui pendekatan folkloris atau cerita rakyat dari generasi ke generasi sebagai penelitian fenomenologi sejarah. Oleh karena itu, peneliti yakin bahwa penelitian yang serupa tidak ditemukan.

Fokus masalah dalam penelitian ini adalah membahas tentang pelaksanaan budaya Telonan dan Tingkeban di Dusun Kunti-Desa Mranggen-Kecamatan Purwoasri-Kabupaten Kediri-Jawa Timur. Termasuk di dalamnya adalah tentang nilai-nilai yang terkandung dari budaya tersebut. Tujuan dari penelitian ini adalah untuk mengetahui implementasi dan nilai yang terkandung dari budaya Telonan dan Tingkeban di Dusun Kunti-Desa Mranggen-Kecamatan Purwoasri-Kabupaten KediriJawa Timur. Penelitian ini diharapkan dapat memberikan manfaat untuk menambah pengetahuan dan wawasan tentang akulturasi budaya yang berkembang di Indonesia, khususnya di Jawa sebagai salah satu upaya dalam melestarikan budaya Nusantara, serta diharapkan dapat membantu memberikan pemahaman akan pentingnya melestarikan budaya selama tidak menyimpang dari ajaran Islam.

\section{B. Metode Penelitian}

Di dalam artikel ini, peneliti menggunakan jenis penelitian kualitatif dengan pendekatan folkloris. Penelitian dilakukan dengan berusaha memahami sistem budaya, kolektivitas, pewarisan, konservasi, dan pemanfaatannya yang ada di masyarakat, baik secara fakta dan data dalam penelitian. Dengan demikian penelitian ini merupakan penelitian deskriptif kualitatif, sehingga

4 "NELONI, MITONI ATAU TINGKEBAN: (Perpaduan Antara Tradisi Jawa Dan Ritualitas Masyarakat Muslim) | Adriana | KARSA: Journal of Social and Islamic Culture,” accessed June 11, 2019, http://ejournal.stainpamekasan.ac.id/index.php/karsa/article/view/69.

5 “NILAI ETIK YANG TERKANDUNG DALAM UPACARA TINGKEBAN | Purwastuti | Jurnal Cakrawala Pendidikan," accessed June 11, 2019, https://journal.uny.ac.id/index.php/cp/article/view/8727/pdf. 
semua pemahaman, penjelasan, dan temuan didesripsikan dalam bentuk uraian kalimat-kalimat sebagai hasil penafsiran secara kritis argumentatif berdasarkan data penelitian. Data primer diperoleh melalui observasi lapangan dan wawancara dengan informan yang ditetapkan secara purposive. Sedangkan data sekunder diambil dari berbagai sumber tertulis maupun dokumentasi. Data primer dikumpulkan melalui indepth interview, pemotretan, dan pencatatan. Data yang terkumpul diolah secara kualitatif melalui model Miles dan Hubberman yang meliputi pengumpulan data, display data, reduksi data, dan verifikasi penggambaran simpulan dengan keterkatitannya. Setelah itu dilakukan analisis deskriptif.

Validitas dalam penelitian ini menggunakan model triangulasi, artinya pemeriksaan keabsahan data yang memanfaatkan sesuatu yang lain dalam membandingkan hasil wawancara terhadap objek penelitian. Triangulasi sendiri menurut Endraswara ada tiga macam. Jika yang diperlukan triangulasi data, dapat dilakukan dengan cara mencari data-data lain sebagai pembanding. Orang yang terlibat dapat dimintai keterangan lebih lanjut tentang data yang diperoleh. Jika triangulasi pada aspek metode, perlu meninjau ulang metode yang digunakan (dokumentasi, observasi, catatan lapangan, dan lain-lain). ${ }^{6}$

Penelitian ini dilakukan terhadap sekelompok masyarakat yang meyakini ritual yang sama dan mereka melakukannya turun temurun sejak dulu. Mereka adalah masyarakat desa Kunti yang dalam penelitian folklor ini selanjutnya disebut sebagai obyek penelitian (sumber data). Sumber data dalam penelitian ini adalah informan yang terlibat dan memiliki pengetahuan tentang rangkaian upacara yakni, sesepuh, perangkat desa, pemimpin acara, dan warga desa Kunti. Sumber data ini kemudian dicatat melalui catatan tertulis atau dengan rekaman video/ audio, dan pengambilan foto. Dalam penelitian ini, penentuan responden atau informan dilakukan dengan teknik snowball sampling. Teknik snowball sampling merupakan teknik pemilihan responden yang diawali dari jumlah kecil, misalnya dua orang, dan kemudian atas dasar rekomendasinya ditunjuk responden lain, dan model rekomendasi tersebut terus dilakukan sampai akhirnya diperoleh jumlah responden dan sejumlah informasi yang diperlukan. Berkaitan dengan snowball sampling ini peneliti menentukan satu informan kunci yang kedudukannya sebagai pemberi informasi pertama dan diharapkan dapat merekomendasikan ke beberapa informan lain untuk melengkapi data penelitian. Pemilihan informan kunci dalam penelitian ini berdasarkan dua hal yaitu, memilih orang yang dituakan, dan memilih orang yang dianggap mengerti lebih banyak tentang obyek penelitian yang akan dikaji. Penelitian ini ditempuh kurang lebih hampir satu tahun, sejak September 2017 hingga September 2018. Selain menjadi observer, peneliti juga berperan sebagai partisipan aktif dalam penelitian ini.

\section{Pembahasan atau Analisis Islam dan Budaya Jawa}

Pengertian akulturasi budaya (acculturation) adalah perpaduan di antara unsur-unsur kebudayaan yang berbeda dan bersatu dalam upaya membentuk kebudayaan baru tanpa dengan maksud menghilangkan kepribadian kebudayaannya yang asli. ${ }^{7}$ Definisi akulturasi ini tentunya berbalik dengan asimilasi, yang mana pengertian asimilasi adalah adanya penggabungan dua kebudayaan baru dan menghilangkan kebudayaan yang lama. ${ }^{8}$

\footnotetext{
${ }^{6}$ Suwardi Endraswara, Metodologi penelitian kebudayaan, 2017, 46.

${ }^{7}$ Abdurrahmat Fathoni, Antropologi Sosial Budaya Suatu Pengantar (Jakarta: Rineka Cipta, 2006), 3.

${ }^{8}$ Koentjaraningrat Koentjaraningrat, Pengantar Ilmu Antropologi (Jakarta: Aksara Baru, 1990), 67.
} 
Contoh akuturasi budaya yang sering kita temukan dalam kehidupan, misalnya saja adanya perpaduan antar musik melayu yang kemudian bertemu dengan musik Spanyol. Perpaduan kedua musik ini pada akhirnya menghasilkan musik keroncong, yang mana musik keroncong sebenarnya adalah bagian daripada kedua musik akan tetapi tidak menghilangkan ciri khasnya. Contoh lain dari akulturasi budaya di Indonesia misalnya adanya sistem dakwah melalui wayang, seni bangunan masjid dengan atap tumpang yang menunjukkan adanya akulturasi Islam dengan budaya Hindu.

Masuknya Islam ke Jawa, dalam konteks kebudayaan membawa dampak pada akulturasi Islam dan budaya Jawa, yaitu budaya yang telah hidup dan berkembang selama masa kejayaan kerajaankerajaan Hindu Jawa. Akulturasi Islam dan budaya Jawa dapat dilihat pada batu nisan, arsitektur (seni bangunan), seni sastra, seni ukir, dan berbagai tradisi perayaan hari-hari besar Islam. Akulturasi Islam dan budaya Jawa dapat dilihat dalam setiap era kesultanan (kerajaan Islam) yang ada di Jawa, baik era Demak, era Pajang, maupun era Mataram Islam. Pada era Demak, akulturasi antara Islam dan budaya Jawa terjadi dalam banyak hal, misalnya, arsitektur, seni ukir, kesenian wayang, pola pemakaman, dan seni sastra (seperti babad, hikayat, dan lainnya). Berbagai hasil akulturasi Islam dan budaya Jawa tersebut dijadikan sarana bagi penanaman nilai-nilai Islam ke dalam masyarakat Jawa. ${ }^{9}$

Tradisi masyarakat Jawa yang masih dilaksanakan secara turun menurun salah satunya adalah slametan. Slametan adalah proses mistik yang mana merupakan tahap awal dari proses dalam pencarian keselamatan (slamet), yang kemudian diikuti oleh mayoritas orang Jawa untuk menuju tahap yang paling akhir, kesatuan kepada Tuhan. Slametan merupakan bentuk penerapan sosioreligius orang Jawa, praktek penjamuan yang dilaksanakan bersama-sama dengan para tetangga, dan keluarga. Slametan dilaksanakan berkaitan dengan tata upacara. Dapat dikatakan bahwa tradisi slametan adalah hal yang perlu dilakukan untuk bersedekah dan dapat digunakan sebagai simbolis penolak bala bagi keluarga yang mengadakan selamatan. Selametan dilakukan untuk acara-acara di Jawa baik yang berkaitan dengan kelahiran, kematian, tasyakuran, atau pun pernikahan. ${ }^{10}$

Pengertian Islam secara harfiyah artinya damai, selamat, tunduk, dan bersih. Dari pengertian Islam secara bahasa ini, dapat disimpulkan Islam adalah agama yang membawa keselamatan hidup di dunia dan di akhirat.

Menurut istilah, Islam adalah ketundukan seorang hamba kepada wahyu Ilahi yang diturunkan kepada para nabi dan rasul khususnya Muhammad saw. guna dijadikan pedoman hidup dan juga sebagai hukum/ aturan Allah swt. yang dapat membimbing umat manusia ke jalan yang lurus, menuju ke kebahagiaan dunia dan akhirat. Secara istilah juga, Islam adalah agama terakhir yang diturunkan Allah swt. kepada Nabi Muhammad saw. sebagai nabi dan utusan Allah (Rasulullah) terakhir untuk umat manusia, berlaku sepanjang zaman, bersumberkan Al-Quran dan As-Sunnah.

Islam sebagaimana dikemukakan di atas, adalah agama yang memiliki ajaran luhur. Apabila ajaran-ajaran Islam diketahui dan diamalkan setiap orang yang meyakininya (pemeluknya), maka ia akan menuai rasa aman dan damai dalam hidupnya. Islam adalah agama yang berisi ajaran yang lengkap (holistik), menyeluruh (comprehensive) dan sempurna (kamil). Sebagai agama sempurna, Islam datang untuk menyempurnakan ajaran yang dibawa oleh Nabi-nabi Allah sebelum Nabi Muhammad. Kesempurnaan ajaran ini menjadi misi profetik (nubuwwah) kehadiran Nabi Muhammad saw.

9 Musyrifah Sunanto, Sejarah Peradaban Islam Indonesia (Jakarta: Divisi Buku Perguruan Tinggi, RajaGrafindo Persada, 2005), 43.

${ }^{10}$ Yana Yana, Falsafah Dan Pandangan Hidup Orang Jawa (Yogyakarta: Bintang Cemerlang, 2012), 25. 
Budaya lokal adalah kebudayaan yang tumbuh dan berkembang serta dimiliki dan diakui oleh masyarakat suku bangsa setempat. Budaya lokal biasanya tumbuh dan berkembang dalam suatu masyarakat suku atau daerah tertentu karena warisan turun-temurun yang dilestarikan. Budaya daerah ini akan muncul pada saat penduduk suatu daerah telah memiliki pola pikir dan kehidupan sosial yang sama, sehingga menjadi suatu kebiasaan yang membedakan mereka dengan pendudukpenduduk yang lain. Budaya daerah mulai terlihat berkembang di Indonesia pada zaman kerajaankerajaan terdahulu. Hal itu dapat dilihat dari cara hidup dan interaksi sosial yang dilakukan masingmasing masyarakat kerajaan di Indonesia yang berbeda satu sama lain.

Sebelum agama Hindu masuk ke tanah Jawa penduduk lokal sudah menganut kepercayaan yaitu agama Kejawen. Yakni suatu kepercayaan yang dipengaruhi oleh kekuatan alam, benda-benda yang dianggap magis, roh leluhur, mahluk halus pengganggu (lelembut) dan mahluk halus yang mempunyai kedudukan tertinggi yaitu danyang. Selain itu juga banyak ritual-ritual sakral yang dilakukan sebagai persembahan sekaligus meminta perlindungan agar dijauhkan dari mara bahaya dan bencana. Dengan adanya kepercayaan yang terus berlangsung maka terbentuklah suatu kebudayaan serta mendorong munculnya hukum adat. ${ }^{11}$

Agama Islam masuk di Jawa pada awal abad XII, tetapi islamisasi baru dimulai secara intensif pada abad XIV. Di Jawa, penyebar Islam dikenal dengan sebutan walisongo (wali sembilan). Penyebaran dilakukan dengan cara damai dan menarik, sehingga tidak terasa adannya perbedaan antara agama yang telah mereka peluk dengan agama baru (Islam). Penyebaran Islam di Jawa timur khususnya dan pulau Jawa umumnya dilakukan dengan pendekatan sosio teologi yakni memperhatikan kondisi masyarakat dan kondisi kepercayaan yang hidup dalam masyarakat. Para Wali dan penyebar Islam seterusnya justru menempatkan diri bukan sebagai orang asing, melainkan dengan jalan membaurkan diri dengan masyarakat.

Proses perkembangan awal Islam di Indonesia tak bisa dilepaskan dari ajaran tasawuf (sufisme). Tasawuf memegang peranan yang sangat penting bagi perkembangan Islam di negeri ini utamanya di pulau Jawa. Jauh sebelum orang- orang Jawa mengenal ajaran-ajaran tasawuf (Islam) yang dikembangkan oleh para ulama' dan mubaligh Islam (para Wali), mereka telah akrab dengan kebudayaan mereka sendiri yang khas dengan animisme dan dinamismenya dikalangan rakyat serta Hinduisme Buddhisme dikalangan elit istana. Kebudayaan ini memiliki ciri yang khas dan halus dan sangat terbuka, sehingga memungkinkan unsur-unsur luar tak kesulitan untuk masuk kedalamnya melalui sinkretisasi atau akulturasi. Dengan pola perkembangan yang seperti ini, Islam di Jawa memiliki ciri khas. Banyak upacara-upacara dan kegiatan-kegiatan ritualistik yang sebenarnya merupakan produk animisme, dinamisme, Hinduisme dan Buddhisme dipertahankan dan dibingkai dengan nilai-nilai Islam, seperti dengan pemberian doa secara Islam dan tradisi kenduri, selamatan, dan lain-lain.

Studi foklor sebagai sarana komunikasi berbudaya. Karena begitu banyaknya tradisi lisan masyarakat Indonesia yang belum terungkap, menjadikan inspirasi yang menarik untuk dieksplor dan diekspos pada khalayak umum sebagai khasanah pengembangan ilmu budaya. Studi foklor adalah studi perilaku budaya masyarakat yang hidup menetap secara berkelompok di masyarakat.

Secara etimologi kata "foklor" adalah pengindonesiaan kata bahasa Inggris folklore. ${ }^{12}$ Kata ini adalah kata majemuk, yang berasal dari dua kata dasar folk dan lore. Folk adalah sekelompok orang

\footnotetext{
${ }^{11}$ Rois Mahfud, Al-Islam: pendidikan agama Islam (Jakarta: Penerbit Erlangga, 2011), 53.

12 Alan Dundes, The Study of Folklore (New Jersey: Prentice Hall, 1965), 12.
} 
yang memiliki ciri-ciri pengenal fisik, sosial, dan budaya sehingga dapat dibedakan dari kelompokkelompok lainnya. Ciri- ciri pengenal itu antara lain dapat berwujud warna kulit, bentuk rambut yang sama, mata pencaharian yang sama, bahasa yang sama, taraf pendidikan yang sama, dan agama atau kepercayaan yang sama. Namun, yang lebih penting lagi adalah bahwa mereka telah memiliki suatu tradisi, yakni kebiasaan yang telah mereka warisi turun temurun, ${ }^{13}$ sedikitnya dua generasi,yang dapat mereka akui sebagai milik bersama mereka. ${ }^{14}$ Di samping itu, mereka sadar akan identitas kelompok mereka sendiri. Jadi folk adalah sinonim dengan kolektif, yang juga memiliki cirri-ciri pengenal fisik atau kebudayaan yang sama serta mempunyai kesadaran kepribadian sebagai kesatuan masyarakat. Lore adalah kebiasaan folk, yaitu sebagian kebudayaannya, yang diwariskan secara turun-temurun secara lisan atau melalui suatu contoh yang disertai gerak isyarat atau alat pembantu pengingat. ${ }^{15}$

Dari uraian di atas dapat didefinisikan bahwa folklor adalah sebagian kebudayaan suatu kolektif, yang tersebar dan diwariskan secara turun-temurun, di antara kolektif macam apa saja, secara tradisional dalam versi yang berbeda, baik dalam bentuk lisan maupun contoh yang disertai dengan gerak isyarat atau alat pembantu pengingat. ${ }^{16}$

\section{Akulturasi Budaya Telonan dan Tingkeban di Dusun Kunti-Desa Mranggen-Kecamatan Purwoasri- Kabupaten Kediri-Jawa Timur}

Desa Mranggen terletak di daerah Kediri bagian utara, tepatnya di kecamatan Purwoasri, sekitar 21 kilometer dari pusat Kota Kediri. Desa ini berada di sebelah timur sungai Brantas yang terbagi menjadi 4 dusun, yaitu dusun Mranggen, dusun Jenjem, dusun Salam, dan dusun Kunti yang menjadi obyek penelitian ini. Sebagian besar penduduknya bermata pencaharian sebagai petani. Kondisi keagamaan masyarakat khususnya dusun Kunti sudah sangat religius, meski sebagian dari mereka masih memegang budaya Kejawen. ${ }^{17}$ Di dusun ini berkembang berbagai budaya yang merupakan akulturasi budaya Jawa yang dalam pelaksanaannya banyak diwarnai dengan ajaran Islam, seperti Tahlilan, Telonan, Tingkeban, Nyadranan, serta masih banyak lagi.

Di wilayah Kunti ini peneliti memilih salah satu budaya yang berkembang di masyarakat, yaitu "Telonan dan Tingkeban." Telonan adalah kegiatan mendoakan ibu yang sedang hamil beserta bayi yang dikandungnya saat usia kandungan mencapai 3 bulan memasuki 4 bulan. Sedangkan Tingkeban dilaksanakan pada saat usia kandungan mencapai 7 bulan. Kegiatan ini dilaksanakan dengan tujuan agar ibu dan bayi senantiasa diberi keselamatan dan kesehatan oleh Allah, serta kelancaran dalam proses melahirkan janinnya nanti.

Tradisi telonan dan tingkeban merupakan warisan budaya nenek moyang zaman dulu. Mereka meyakini bahwa ada kekuatan yang menguasai manusia di luar diri mereka. Mereka selalu meminta kepada kekuatan yang mereka anggap Tuhan itu untuk mengabulkan keinginan-keinginan mereka. Mereka berdoa dengan menggunakan simbol-simbol seperti buceng ketan atau buceng kuat, dengan harapan ibu yang mengandung diberi kekuatan. Jenang merah dan jenang putih yang disebut jenang sengkala, sebagai simbol untuk menolak mala petaka. Cara nenek moyang menghidangkan aneka

${ }^{13}$ Suwardi Endraswara, Folklor Nusantara: Hakikat, Bentuk, Dan Fungsi (Yogyakarta: Ombak, 2013 ), 31.

${ }^{14}$ Suwardi Endraswara, Buku Pinter Budaya Jawa: Mutiara Adiluhung Orang Jawa, Cet. 1 (Yogyakarta: Gelombang Pasang, 2005), 31.

${ }^{15}$ Sjamsuddhuha Sjamsuddhuha, Corak Dan Gerak Hinduismme Dan Islam Di Jawa Timur (Surabaya: Suman Indah, 1990), 32.

${ }^{16}$ Simuh Simuh, Islam Dan Pergumpulan Budaya Jawa (Yogyakarta: Teraju, 2003), 45.

${ }^{17}$ Sri Wahyuni, Hasil wawancara dengan Kaur, June 4, 2018. 
makanan ini adalah dengan menaruhnya di dekat pohon besar, batu besar, atau patung yang mereka anggap sebagai Tuhan. ${ }^{18}$

Di saat tradisi seperti ini sedang marak, kemudian ada beberapa orang yang disebut sebagai "Pujonggo atau Perjonggo". Mereka adalah orang-orang yang telah mendapatkan pendidikan dari mursyid (guru) mereka. Mereka kemudian mempelajari maksud dan tujuan orang-orang daerah yang melestarikan budaya telonan dan tingkeban. Menurut hasil analisis mereka, sebenarnya tujuan budaya ini baik. Akhirnya para Pujonggo mengarahkan atau memberi wawasan kepada masyarakat agar budaya telonan dan tingkeban ini dapat dilaksanakan sesuai nilai-nilai ajaran Islam. Di antara perubahan yang dilakukan para Pujonggo adalah mengganti kalimat pemujaan dengan kalimat thoyyibah (bacaan dzikir dan ayak-ayat suci alquran). Selain itu, bahan-bahan makanan yang dijadikan sesajen oleh warga, oleh para pujonggo diarahkan sebagai sedekah yang dibagikan kepada warga yang hadir untuk dibawa pulang. Karena budaya baru yang diwarnai nilai-nilai Islami ini dianggap baik oleh warga, maka budaya ini dilestarikan oleh generasi-generasi selanjutnya sampai saat ini. ${ }^{19}$

Tradisi telonan \& tingkeban dimulai dengan menyiapkan bahan-bahan yang dibutuhkan mulai dari jenang, nasi, rujak, dan dawet. Dalam pelaksanaan telonan \& tingkeban ini dihidangkan beberapa jenis makanan khas Jawa seperti jenang merah, jenang putih, buceng ketan, keleman, timun, sego golong, sego semaron, sego rogoh, gedhang setangkep, dawet, dan rujak. Jenang merah adalah olahan nasi yang ditanak bersama gula merah. Buceng ketan adalah hidangan berupa beras ketan yang telah ditanak kemudian dibungkus dengan daun pisang. Keleman merupakan hasil bumi yang direbus berupa kacang tanah, dan umbi-umbian. Sego golong adalah hidangan berupa nasi yang dibungkus kecil-kecil, biasanya jumlahnya 7 atau 9. Sego semaron adalah hidangan berupa nasi yang diletakkan pada sebuah adah atau disebut maron, kemudian diberi lauk pauk seperti mi, sambal goreng, dan ayam ingkung (ayam utuh yang diolah dan dibumbui). ${ }^{20}$

Kemudian para tetangga diundang ke rumah untuk mendoakan ibu hamil dan janin yang dikandung. Acara ini dimulai dengan membacakan ayat-ayat suci alquran dan kalimat thayyibah. Setelah selesai, tuan rumah membagikan makanan yang telah disiapkan kepada para undangan untuk dibawa pulang.

Berdasarkan hasil observasi peneliti, peneliti menyimpulkan bahwa perbedaan antara Telonan dan tingkeban adalah terletak pada waktu pelaksanaannya. Telonan dilaksanakan saat usia kandungan ibu hamil memasuki usia 4 bulan. Sedangkan Tingkeban dilaksanakan saat usia kandungan ibu hamil mencapai 7 bulan. Selain itu, jika dalam tingkeban disertakan hidangan dawet dan rujak, maka dalam tradisi telonan, dua hidangan ini tidak ada.

Berdasarkan hasil wawancara, observasi, serta partisipasi peneliti selama ini, peneliti dapat mendeskripsikan nilai-nilai yang terkandung dari budaya Telonan dan Tingkeban di Dusun Kunti. Nilai-nilai tersebut adalah: a) Tolong menolong. Nilai ini bisa kita lihat dari awal persiapan acara ini, yang membutuhkan bantuan para tetangga atau sanak saudara, b) Ajang silaturrahim. Era globalisasi yang penuh tantangan disrupsi ini, rentan sekali membuat manusia menjadi individualisme. Manusia sibuk dengan pekerjaan masing-masing, dan bahkan asyik dengan gadget masing-masing. Adanya acara Telonan dan tingkeban dapat menjadi ajang silaturrahim dan saling mengenal satu sama lain, c) Meningkatkan nilai religiusitas, yaitu hablumminallah dan

\footnotetext{
${ }^{18}$ Maesaroh, Hasil wawancara dengan pemimpin acara telonan \& tingkeban, July 5, 2018.

${ }^{19}$ Sutini, Hasil wawancara dengan sesepuh Dusun Kunti, July 4, 2018.

${ }^{20}$ Khumaidah, Hasil wawancara dengan salah satu jamaah acara telonan \& tingkeban, July 9, 2018.
} 
hablumminannas. Hablumminallah karena para tamu undangan yang hadir membacakan beberapa ayat alquran dan kalimat thoyyibah, yang artinya dia berdzikir kepada Allah. Hablumminannas karena mereka mendoakan tuan rumah yang punya hajat, yaitu mendoakan ibu dan janin yang dikandungnya, d) Menghindari sikap tabdzir (pemborosan). Sebelum adanya akulturasi budaya nenek moyang dengan ajaran Islam, makanan-makanan yang dipersiapkan untuk acara seperti ini dibuang begitu saja di bawah pohon besar atau di tempat-tempat yang diakui menyimpan kekuatan ghaib. Namun setelah adanya akulturasi, makanan-makanan yang telah disediakan dialihfungsikan menjadi lahan sedekah bagi tuan rumah. Makanan-makanan tersebut diberikan pada tamu undangan yang datang untuk bisa dibawa pulang. Bahkan biasanya tuan rumah masih menambahkannya dengan sebungkus nasi lengkap dengan lauk pauk, yang disebut berkat.

Menurut cerita rakyat dalam sastra Jawa, Islam datang dan menyebar di Jawa berkat jasa sembilan pendakwah yang disebut walisongo. Dakwah mereka lakukan dengan bijaksana. Apa yang sudah menjadi kebiasaan rakyat tidak diubah dengan kekerasan, tetapi sedikit demi sedikit dibawa dan diarahkan kepada Islam. Berdasarkan fakta tersebut, penulis memiliki anggapan bahwa yang dikatakan pujonggo pembawa ajaran Islam yang pada akhirnya menciptakan akulturasi budaya di Jawa, kemungkinan besar adalah salah satu dari walisongo. ${ }^{21}$

Menurut sejarah masyarakat Jawa, tradisi Telonan \& Tingkeban ini berawal dari masa pemerintahan Prabu Jayabaya. Seorang wanita bernama Niken Satingkep bersuami seorang pemuda bernama Sadya. Niken Satingkep telah melahirkan sebanyak sembilan kali, namun satu pun tidak ada yang hidup. Karena itu keduanya segera menghadap raja Kediri, yaitu Prabu Widayaka (Jayabaya). Oleh Sang Raja, keluarga tersebut disarankan agar menjalani tiga hal, antara lain: perintah mandi besar setiap hari Budha (hari Rabu) sebelum terbenam matahari; setelah mandi memakai pakaian bersih dengan membawa cengkir gading; mengikat daun tebu putih lalu dipotong dengan sebilah keris; dipastikan akan mendapat momongan.

Berdasarkan analisis penulis, pelaksanaan budaya telonan dan tingkeban di Dsn. Kunti, Ds. Mranggen, Kec. Purwoasri, Kab. Kediri sudah mengalami pergeseran. Hal ini disebabkan karena pola pikir masyarakat dusun ini yang religius. Hal-hal yang dianggap mitos sudah tidak dilakukan. Masyarakat desa tersebut membingkai budaya telonan dan tingkeban dengan nilai-nilai ajaran Islam seperti mengganti ritual-ritual seperti yang disebutkan oleh sejarah di atas dengan bacaan-bacaan ayat suci alquran seperti surat Luqman, Yusuf, dan Maryam. Bukan tanpa tujuan, pembacaan suratsurat tersebut dengan harapan anak yang dikandung ibu hamil nantinya akan menjadi anak yang berbakti seperti kisah Lukman di dalam alquran, serta jika laki-laki diharapkan mewarisi ketampanan Yusuf dan kebaikan akhlaknya, jika perempuan diharapkan bisa menjadi teladan seperti Maryam.

Tujuan dari pelaksanaan telonan dan tingkeban bukan lagi mempercayai mitos agar anak yang dikandung tidak mati seperti kisah bayi yang dikandung Niken Satingkep. Tetapi, tujuan diadakannya tradisi telonan dan tingkeban adalah mendoakan janin agar diberikan kelancaran dan keselamatan saat proses kelahiran, serta diberikan nasib baik oleh sang Khaliq. ${ }^{22}$

Selain itu, simbol-simbol makanan yang awalnya hanya digunakan sebagai prosesi ritual semata dan dibuang sia-sia, oleh masyarakat dusun Kunti hal itu tidak dilakukan demikian.

\footnotetext{
21 "WALISONGO: MENGISLAMKAN TANAH JAWA (SUATU KAJIAN PUSTAKA) | Anita | Wahana Akademika: Jurnal Studi Islam Dan Sosial,” accessed June 11, 2019, http://journal.walisongo.ac.id/index.php/wahana/article/view/815.

${ }^{22}$ Suwarna Pringgawidagda, Upacara Tingkeban, Ed. 1., cet. 1 (Yogyakarta: Adicita Karya Nusa, 2003$), 65$.
} 
Makanan-makanan yang dibuat dengan nilai simbolik seperti rujak, keleman, jenang, dll. disedekahkan kepada para tamu undangan yang hadir.

Masyarakat dusun Kunti juga meniadakan paham yang mensyaratkan bahwa tradisi telonan dan tingkeban harus dilaksanakan pada hari-hari yang dianggap sakral, seperti hari Budha atau hari Rabu. Menurut mereka, semua hari di dalam Islam adalah baik. Sehingga tuan rumah (keluarga yang akan mengadakan selametan telonan \& tingkeban) bebas memilih hari disesuaikan dengan kelonggaran waktu yang mereka bisa.

Maka menurut hemat penulis, tradisi ini sah-sah saja untuk dilaksanakan dan dilestarikan selama tidak menjadi beban bagi si ibu janin. Bagaimanapun, tidak ada kewajiban harus melaksanakan tradisi ini menurut ajaran Islam. Sehingga, jika seandainya ibu janin sedang dalam keadaan kurang mampu untuk melakukan acara telonan atau tingkeban dengan mengundang para tetangga, maka tidak mengapa acara ini tidak dilakukan. Karena sebenarnya, mendoakan janin bisa dilakukan oleh si ibu hamil itu sendiri tanpa mengundang para tetangga dengan serangkaian ritus acara telonan. Sekali lagi, ini adalah bentuk akulturasi budaya yang ada di Jawa, bukan ibadah yang diwajibkan dalam Islam.

\section{Kesimpulan dan Saran}

Salah satu bentuk akulturasi budaya Jawa dengan Islam di Dusun Kunti adalah tradisi Telonan dan Tingkeban. Tradisi ini dilaksanakan dengan tujuan mendoakan ibu yang sedang hamil saat janinnya berusia 4 bulan dan 7 bulan. Kegiatan ini dilaksanakan dengan tujuan agar ibu dan bayi senantiasa diberi keselamatan dan kesehatan oleh Allah, serta kelancaran dalam proses melahirkan janinnya. Meski dalam pelaksanaannya, tradisi telonan dan tingkeban di dusun ini telah mengalami pergeseran nilai. Nilai-nilai yang tidak bertentangan dengan ajaran Islam tetap dilestarikan, sementara yang bertentangan dengan Islam ditinggalkan. Hal ini karena pola pikir masyarakatnya yang religius. Dalam pelaksanaan telonan \& tingkeban ini dihidangkan beberapa jenis makanan khas Jawa sebagai sedekah kepada para tamu undangan, seperti jenang merah, jenang putih, buceng ketan, keleman, timun, sego golong, sego semaron, sego rogoh, gedhang setangkep, dawet, dan rujak. Dalam acara telonan dan tingkeban ini dibacakan beberapa surat dari alquran dan kalimatkalimat thoyyibah dengan tujuan mendoakan ibu dan janin. Nilai-nilai yang terkandung dari acara ini di antaranya: tolong-menolong, kerukunan, silaturrahim, hablumminallah dan hablumminannas.

Akulturasi budaya yang berkembang di masyarakat sarat akan nilai filosofis. Para generasi muda hendaknya memahami nilai-nilai filosofis dari budaya yang berkembang. Jika budaya tersebut tidak bertentangan dengan nilai-nilai ajaran Islam, maka tidak ada salahnya kita berperan serta untuk membina kerukunan dan melestarikannya. Jika ditemukan ada tindakan yang tidak sesuai dengan nilai-nilai ajaran Islam, generasi muda harus berani merekonstruksi budaya tersebut agar sesuai dengan ajaran Islam.

\section{Daftar Pustaka}

Dundes, Alan. The Study of Folklore. New Jersey: Prentice Hall, 1965. Endraswara, Suwardi. Buku Pinter Budaya Jawa: Mutiara Adiluhung Orang Jawa. Cet. 1. Yogyakarta: Gelombang Pasang, 2005.

Endraswara, Suwardi. Folklor Nusantara: Hakikat, Bentuk, Dan Fungsi. Yogyakarta: Ombak, 2013.

Endraswara, Suwardi. Metodologi penelitian kebudayaan, 2017.

Fathoni, Abdurrahmat. Antropologi Sosial Budaya Suatu Pengantar. Jakarta: Rineka Cipta, 2006. 
Habib Shulton, S. H. I. Runtuhnya Keadilan Perempuan (Kritik UU.No. 1 Tahun 1974 Tentang Perkawinan Perspektif Hak Asasi Manusia). Lintang Rasi Aksara, 2018.

//library.iaimnumetrolampung.ac.id/index.php?p=show_detail\&id=33681\&keywords=runtu hnya+keadilan.

Herawati, Nanik. Mutiara Adat Jawa 2. Klaten: PT Intan Pariwara, 2010.

Isnawan, Fuadi. "Program Deradikalisasi Radikalisme Dan Terorisme Melalui Nilai-Nilai Luhur Pancasila.” FIKRI : Jurnal Kajian Agama, Sosial Dan Budaya 3, no. 1 (July 31, 2018): 128. https://doi.org/10.25217/jf.v3i1.275.

Khumaidah. Hasil wawancara dengan salah satu jamaah acara telonan \& tingkeban, July 9, 2018. Koentjaraningrat, Koentjaraningrat. Pengantar Ilmu Antropologi. Jakarta: Aksara Baru, 1990. Maesaroh. Hasil wawancara dengan pemimpin acara telonan \& tingkeban, July 5, 2018. Mahfud, Rois. Al-Islam: pendidikan agama Islam. Jakarta: Penerbit Erlangga, 2011.

"NELONI, MITONI ATAU TINGKEBAN: (Perpaduan Antara Tradisi Jawa Dan Ritualitas Masyarakat Muslim) $\mid$ Adriana | KARSA: Journal of Social and Islamic Culture.” Accessed June 11, 2019. http://ejournal.stainpamekasan.ac.id/index.php/karsa/article/view/69.

"NILAI ETIK YANG TERKANDUNG DALAM UPACARA TINGKEBAN | Purwastuti | Jurnal Cakrawala Pendidikan." Accessed June 11, 2019. https://journal.uny.ac.id/index.php/cp/article/view/8727/pdf.

"PENDIDIKAN ISLAM DI INDONESIA DALAM LINTASAN SEJARAH (Perspektif Kerajaan Islam) $\mid$ Nursyarief $\mid$ Lentera Pendidikan : Jurnal Ilmu Tarbiyah Dan Keguruan.” Accessed June 11, 2019. http://journal.uinalauddin.ac.id/index.php/lentera_pendidikan/article/view/533.

Prasetawati, Eka, and Habib Shulton Asnawi. "Wawasan Islam Nusantara; Pribumisasi Nilai-Nilai Kearifan Lokal Di Indonesia." FIKRI : Jurnal Kajian Agama, Sosial Dan Budaya 3, no. 1 (July 31, 2018): 219-58. https://doi.org/10.25217/jf.v3i1.283.

Pringgawidagda, Suwarna. Upacara Tingkeban. Ed. 1., cet. 1. Yogyakarta: Adicita Karya Nusa, 2003.

"REKONSTRUKSIHUKUM ISLAM DANIMPLIKASI SOSIAL BUDAYA PASCA

REFORMASI DI INDONESIA | Shulhan | KARSA: Journal of Social and Islamic Culture.” Accessed June 11, 2019.

http://ejournal.stainpamekasan.ac.id/index.php/karsa/article/view/41.

Simuh, Simuh. Islam Dan Pergumpulan Budaya Jawa. Yogyakarta: Teraju, 2003.

Sjamsuddhuha, Sjamsuddhuha. Corak Dan Gerak Hinduismme Dan Islam Di Jawa Timur. Surabaya: Suman Indah, 1990.

Sunanto, Musyrifah. Sejarah Peradaban Islam Indonesia. Jakarta: Divisi Buku Perguruan Tinggi, RajaGrafindo Persada, 2005.

Sutini. Hasil wawancara dengan sesepuh Dusun Kunti, July 4, 2018.

Umami, Ida. "Peran Tokoh Agama Dalam Pembinaan Harmonisasi Kehidupan Dan Akhlak Masyarakat Di Kota Metro Lampung." FIKRI : Jurnal Kajian Agama, Sosial Dan Budaya 3, no. 1 (July 31, 2018): 259-76. https://doi.org/10.25217/jf.v3i1.220.

Wahyuni, Sri. Hasil wawancara dengan Kaur, June 4, 2018.

"WALISONGO: MENGISLAMKAN TANAH JAWA (SUATU KAJIAN PUSTAKA) | Anita |

Wahana Akademika: Jurnal Studi Islam Dan Sosial.” Accessed June 11, 2019. http://journal.walisongo.ac.id/index.php/wahana/article/view/815.

Yana, Yana. Falsafah Dan Pandangan Hidup Orang Jawa. Yogyakarta: Bintang Cemerlang, 2012. 
Fikri: Jurnal Kajian Agama, Sosial dan Budaya

Septiana Purwaningrum, Habib Ismail 